\title{
THE INCIDENCE OF UPPER GI DISEASES WITH PATIENTS HAVING DYSPEPSIA ON DIAGNOSTIC ENDOSCOPY: A RETROSPECTIVE STUDY
}

\author{
P. Naresh Kumar'1, P. Karuppasamy²
}

${ }^{1}$ Associate Professor, Department of General Surgery, Sri Venkateshwara Medical College \& Research Centre, Ariyur, Pondicherry. ${ }^{2}$ Assistant Professor, Department of General Surgery, Sri Venkateshwara Medical College \& Research Centre, Ariyur, Pondicherry.

\section{ABSTRACT}

\section{BACKGROUND AND OBJECTIVES}

The Aim of the study is to determine the frequency of diagnosis of significant disease by upper gastrointestinal significant disease endoscopy in adult patients with dyspepsia.

\section{OBJECTIVES}

1. To study the frequency of clinically significant gastrointestinal findings in patients with dyspepsia. 2 . To study the sex differentiation of significant findings in gastrointestinal tract in patients with dyspepsia. 3. To emphasise the importance of endoscopic evaluation as an initial investigation in patients with dyspepsia. 4. To compare and analyse the present study with reference to others studies of yield of endoscopy in patients with dyspepsia.

\section{METHODS: PLACE OF STUDY}

General Surgery Department, Sri Venkateshwara Medical College and Research Centre, Ariyur, Pondicherry.

\section{METHOD OF COLLECTION OF DATA}

The patients presented with pain/discomfort of upper abdomen, nausea, vomiting, bloating/fullness of upper abdomen were evaluated by detailed clinical examination followed by endoscopy after getting written consent from patients. The endoscopy findings of all patients in the study were recorded and evaluated.

\section{Inclusion Criteria}

Patients above 13 years of age. 2. Patients presenting with pain/discomfort of upper abdomen, nausea, vomiting, bloating/fullness of upper abdomen.

\section{Exclusion Criteria}

Patients less than 13 years of age. 2. Pregnant Women.

\section{RESULTS}

Hypothesis 1: Among the 234 subjects with dyspepsia normal study of upper gastrointestinal tract was found in 112 subjects forming 47.8\% of the total population. Hypothesis 2: (The prevalence of dyspepsia is modestly higher in women than in men). Of the 234 subjects 125 subjects were females forming $53.4 \%$ of dyspeptic patients. Hypothesis 3: Among the 234 patients with dyspepsia $27.7 \%$ belong to $36-45$ years age group. The prevalence of dyspepsia in this study is $19.6 \%, 15.3 \%$ and $7.6 \%$ in the age frequencies of 46-55, 55-65, and more than 65 years respectively. Thus the frequency seems to decrease as age increases. Hypothesis 4: (Organic dyspepsia increases with increase in age). Out of 234 subjects, the prevalence of organic dyspepsia or dyspeptic patients with a significant endoscopic findings among the 13 to 25 age group is $8.9 \%$. It increases to $9.4 \%$ and $14.1 \%$ at 26 to 35 and 36-45 years group respectively. In less than 45 years age group there is a slight increase in the prevalence of organic dyspepsia as the age increases. In subjects more than 45 years age, there is a decrease in the prevalence of organic dyspepsia.

\section{INTERPRETATIONS AND CONCLUSIONS}

The prevalence of significant findings in upper gastrointestinal evaluation of dyspeptic patients by endoscopy is relatively higher than the prevalence of normal finding or functional dyspepsia. The prevalence of dyspepsia is modestly higher in the female population compared to males. The prevalence of dyspepsia declines slightly with increase in age. The prevalence of organic dyspepsia increases with age up to mid-forties and thereafter there is a slight decrease in its prevalence. The malignant lesions of the stomach and esophagus is relatively high in the dyspeptic patients in the present study. Thus upper gastrointestinal endoscopy has a vital role in the initial evaluation and investigation of patients with dyspepsia.

\section{KEYWORDS}

Dyspepsia, Endoscopy, Gastric Erosions, Peptic Ulcer, Esophagitis, Gastric Malignancy.

HOW TO CITE THIS ARTICLE: Kumar PN, Karuppasamy P. The incidence of upper GI diseases with patients having dyspepsia on diagnostic endoscopy: a retrospective study. J. Evolution Med. Dent. Sci. 2016;5(17): 818-821, DOI: 10.14260/jemds/2016/189

\section{INTRODUCTION}

The term dyspepsia is used to describe a heterogeneous group of upper abdominal symptoms that may arise due to various

Financial or Other, Competing Interest: None.

Submission 31-12-2015, Peer Review 01-02-2016,

Acceptance 10-02-2016, Published 26-02-2016.

Corresponding Author:

Dr. P. Naresh Kumar,

Sri Venkateshwara Medical College \& Research,

Ariyur, Pondicherry.

E-mail:drnk.2011@gmail.com

DOI: $10.14260 /$ jemds/2016/189 causes.

These include discomfort, pain, fullness, bloating, burning or indigestion. Endoscopy is often the first diagnostic tool in the investigation of dyspepsia.

\section{METHODOLOGY \\ Procedure of Study}

The patients fulfilling the inclusion criteria were selected. History taken with a proforma, physical examination done and endoscopy was performed in endoscopy room. An informed consent is obtained before the procedure. 


\section{REVIEW OF LITERATURE}

\section{History of Endoscope}

In 1868, first practical rigid upper GI endoscope was demonstrated by Kussmaul-when he performed gastroscopy with the help of a cooperative Sword swallower. 1,2,3,4,5,6,7,8

In 1881, Karl Stoerk, an Austrian Laryngologist, examined under dim light the entire length of the oesophagus with a rigid tube. ${ }^{8}$ In 1881, at the same time Johann Von Mikulicz constructed a gastroscope that was angulated to 30 degrees at the distal third of a hollow tube. ${ }^{9,10,11,12}$ During the next 50 years Chevalier Jackson introduced rigid bronchoesophagoscopy and several German physicians built gastroscope, all of which proved to be both impractical and dangerous. ${ }^{13,14}$

A new era for endoscopy began in 1932, when the gastroscope designed by Rudolf Schindler and manufactured by George Wolf in Berlin was introduced. This semi flexible gastroscope was constructed on the principle that a series of convex lenses transmit light without distortion through a flexible tube if the distal portion is not bent beyond a certain angle. ${ }^{15,16}$

In the early 1950s, an intragastric camera was manufactured in Japan. This consisted of a flexible tube with a miniature camera incorporated in its tip. ${ }^{15}$ In 1957, Hirschowitz et al. employed these fibres to construct a flexible fibre optic gastroscope.17,18 In 1969 Charged Couple Device (CCD) was introduced in endoscopic instruments. ${ }^{19,20,21}$

In 1970, the length of the fibroesophagoscope was gradually increased to $105 \mathrm{~cm}$, so that nearly complete inspection of the oesophagus, stomach and duodenum was possible. ${ }^{8}$

In 1980s, Welch Allyn introduced electronic endoscope for clinical trial. ${ }^{9}$ 1980-1990 - Advent of videoendoscopy and endoscopic ultrasonography; 1990-2000 - Explosion of laparoscopic surgery and small bowel Endoscopy; 2000-Video capsule endoscopy was introduced; 2002-Infrared fibre optic endoscope - Angle research center, Hampton, Virginia.

The advent of fibre optic endoscopy is undoubtedly one of the most exciting recent advances in gastroenterology and has markedly increased the diagnostic accuracy for certain diseases. Unfortunately, this improvement has not always been accompanied by a similar benefit in the management of the patient and the accepted indications for endoscopy have frequently not been subjected to controlled clinical trials.

The mortality of the endoscopy varies quite widely in different centres, depending upon the expertise of the endoscopist. The major problems are respiratory (hypoxia due to sedation and aspiration pneumonia), perforation of the oesophagus. Thus all patients presenting with dysphagia should have a barium swallow as an initial investigation to assess the level of stricture and look for unsuspected lesions, such as pharyngeal pouch. Hepatic coma precipitated by sedation in patients with advanced liver disease may also occur.

A wide range of endoscopes are now available and only those long enough to examine the whole of the stomach and upper part of the duodenum should be used $(10 \mathrm{~cm}$ working length).

The most important part of the endoscope is the fibre optic bundle, which consists of more than 2,00,000 glass coated 10 micro meter fibres, bound firmly together in the same spatial relationship, but free in between (a coherent bundle). Some fibres transmit the light; others transmit the image by a series of total internal reflections along the length of the bundle. Each fibre transmits a minute proportion of the image and hence the importance of the constant spatial relationship of the fibres in producing an accurate composite picture. The overall diameter of the shaft is limited to 10$12 \mathrm{~mm}$ for easy passage through the oesophagus. The distal endoscope is flexible and the tip can be angulated acutely in two planes often more than 180 degrees. ${ }^{8}$

The image is focused into the fibre bundle by a distal lens, which may forward viewing (80 to 105 degrees wide angle lens) or side viewing when it is set at the right angles to the direction of the fibre bundle. Attempts have also been made to combine the advantages of the end viewer and side viewer by setting the lens obliquely at the tip of the instrument (Field of view 90 degrees diagonally, 60 degrees vertically and horizontally) in all circumstances other than endoscopic cannulation of the ampulla, the procedure should use the forward or forward oblique endoscope which allows examination of the oesophagus.

There are potential areas of the stomach, the proximal portion of the duodenal bulb and the upper portion of the second part of the duodenum that may be difficult to see with this instrument.

These blind spots have been reduced by increasing the angle of view of the modern end viewing endoscopes and the smallest diameter (P scope) can often be inverted with the bulb and the second part of the duodenum to provide a good view of the whole mucosa in this region. Nevertheless, all trained endoscopists are also familiar with the side viewing endoscope, which provide a good view of the stomach and duodenal bulb. Ulcers surrounded by oedematous fold are often more easily seen 'en face' with side viewing endoscopes. Inverting the endoscope to view the Fundus (J manoeuvre) is now a routine part of the examination of the stomach and is made simple by the modern with increased tip flexibility.

The most modern instrument has a common channel to insufflate air or water to cleanse the lens and a separate suction and biopsy tunnel. Immediate cleansing of both channels after endoscopy is an essential ritual to prevent clogging with mucus or blood, this result in need for extensive repair by the manufacturers. The most endoscopy units have now trained nursing personnel familiar with the techniques involved. However, these delicate and highly expensive instruments are also used in emergencies in out of duty hours and it is imperative that anyone using the endoscope be familiar with the cleaning routine.8,11

Biopsy forceps consists of sharpened cusps controlled by a flexible cable. Often there is a central spike between the cusps that enables larger specimens to be taken and is also helpful when lesions/are biopsied tangentially. Cytology brushes have covering sleeve that protects the sample during withdrawal.8,11

\section{AIMS AND OBJECTIVES \\ Aim of the Study}

The Aim of the study is to determine the frequency of diagnosis of significant disease by upper gastrointestinal significant disease endoscopy in adult patients with dyspepsia.

\section{OBJECTIVES}

- To study the frequency of clinically significant gastrointestinal findings in patients with dyspepsia. 
- To study the sex differentiation of significant findings in gastrointestinal tract in patients with dyspepsia.

- To emphasise the importance of endoscopic evaluation as an initial investigation in patients with dyspepsia.

- To compare and analyse the present study with reference to others studies of yield of endoscopy in patients with dyspepsia.

\section{MATERIALS AND METHODS}

\section{Place of Study}

General Surgery Department, Sri Venkateshwara Medical College and Research Centre, Ariyur, Pondicherry.

\section{Method of Collection of Data}

The patients presented with pain/discomfort of upper abdomen, nausea, vomiting, bloating/fullness of upper abdomen were evaluated by detailed clinical examination followed by endoscopy after getting written consent from patients. The endoscopy findings of all patients in the study were recorded and evaluated.

\section{Inclusion Criteria}

- Patients above 13 years of age.

- Patients presenting with pain/discomfort of upper abdomen, nausea, vomiting, bloating/fullness of upper abdomen.

\section{Exclusion Criteria}

- Patients less than 13 years of age.

- Pregnant women.

\section{DISCUSSION}

The dyspeptic patients, their age, sex and endoscopic findings were recorded in a proforma. The prevalence of dyspepsia among different age groups and both the sexes were derived from the data collected. The prevalence of all the significant lesions in endoscopy was derived and their age and sex distribution was charted out. All the data tables and interpretations are presented at the observation and results chapter.

Now let us discuss the results of the present study with literature background and compare with hypothesis.

\section{Hypothesis 1}

(The frequency of diagnosis of clinically significant disease by upper gastrointestinal endoscopy in patients with dyspepsia is less compared to frequency of normal study at endoscopy).

Among the 234 subjects with dyspepsia normal study of upper gastrointestinal tract was found in 112 subjects forming $47.8 \%$ of the total population (Table 5). The above results almost go in accordance with the study of Kenneth R McQuaid et al., which concluded saying that over $50 \%$ to $70 \%$ patients with dyspepsia have no significant focal or structural lesion in the upper gastrointestinal tract at endoscopy.

Among the 234 patients 122 (Table 5) had significant findings forming $52.1 \%$ of the dyspeptic population. This result is not in accordance with the study of Kenneth $\mathrm{R}$ McQuaid et al. which states that an organic cause is found only in $40 \%$ of the patients with dyspepsia.

The difference between them can be explained by the facts that: 1 . The sample size of the present study is relatively small compared to other studies. 2. Sri Venkateshwara Medical College Hospital being a tertiary centre specialized in surgical field the referrals tends to have more significant findings as the referrals are generally patients who have failed some sort of conservative treatment offered by general practitioners in the community. But the present study goes in accordance with the study of Thomson AB, et al. which concluded that significant findings were identified in $58 \%$ of the dyspeptic patients.

\section{Hypothesis 2}

(The prevalence of dyspepsia is modestly higher in women than in men). Of the 234 subjects 125 subjects were females forming $53.4 \%$ of dyspeptic patients (Table 2). This result goes in accordance with Kenneth R McQuaid et al. stating that there is a modestly higher prevalence of dyspepsia in females compared to males.

\section{Hypothesis 3}

(The prevalence of dyspepsia declines slightly as age increases). Among the 234 patients with dyspepsia $27.7 \%$ belong to 36-45 years age group. The prevalence of dyspepsia in this study is $19.6 \%, 15.3 \%$ and $7.6 \%$ in the age frequencies of 46-55, 55-65 and more than 65 years respectively. Thus the frequency seems to decrease as age increases.

\section{Hypothesis 4}

(Organic dyspepsia increases with increase in age). Out of 234 subjects, the prevalence of organic dyspepsia or dyspeptic patients with a significant endoscopic findings among the 13 to 25 age group is $8.9 \%$. It increases to $9.4 \%$ and $14.1 \%$ at 26 to 35 and $36-45$ years group respectively. In less than 45 years age group, there is a slight increase in the prevalence of organic dyspepsia as the age increases. In subjects more than 45 years age, there is a decrease in the prevalence of organic dyspepsia.

Among the various endoscopically significant findings gastric erosions and esophagitis forms 14.1 and 15.3 percentage of the entire dyspeptic population and becomes the most common organic cause of dyspepsia in the study. This result goes in accordance with Kenneth R McQuaid et al. study which gives data stating that the evidence of esophagitis is present in $15 \%$ of patients with dyspepsia.

Duodenal and gastric ulcer forms together around $8 \%$ of the dyspeptic population in the present study. In the Thomson $\mathrm{AB}$ et al. study, the prevalence of peptic ulcer diseases were around $5.3 \%$ and the Wai CT, et al. study showed a prevalence of $14.9 \%$ for peptic ulcer disease among the dyspeptic patients. In the present study, the prevalence is at midpoint with respect to the above two studies.

In the present study, the prevalence of gastric malignancy and esophageal malignancy is around $4.7 \%$ and $1.2 \%$ respectively, which is of a higher range compared with the other studies. In Wai CT, et al. study the prevalence of both gastric and esophageal malignancy was $0.47 \%$ of the dyspeptic population.

The frequency of occurrence of gastric malignancy increases after 45 years of age in this study. At 36-45, 45-55, 55-65 and more than 65 years groups the prevalence of gastric malignancy is $0.4 \%, 0.8 \%, 1.2 \%$ and $2.1 \%$ respectively and is in accordance with the Wai CT, et al. study.

According to his study, the age threshold of 45 years is reasonable for screening of growth in stomach, by endoscopy, as the prevalence increases as age increases more than 45 . 


\section{CONCLUSION}

The prevalence of significant findings in upper gastrointestinal evaluation of dyspeptic patients by endoscopy is relatively higher than the prevalence of normal finding or functional dyspepsia. The prevalence of dyspepsia is modestly higher in the female population compared to males. The prevalence of

dyspepsia declines slightly with increase in age. The prevalence of organic dyspepsia increases with age up to midforties and thereafter there is a slight decrease in its prevalence. The malignant lesions of the stomach and esophagus is relatively high in the dyspeptic patients in the present study. Thus upper gastrointestinal endoscopy has a vital role in the initial evaluation and investigation of patients with dyspepsia.

\section{PROFORMA}

\section{Clinical Study}

Name:

Sex:

Age.

IP No.

Endoscopy No: Occupation.

Locality:

\section{Presenting Complaints}

1. Pain/discomfort upper Abdomen []

2. Nausea or Vomiting []

3. Early satiety []

4. Upper abdomen fullness []

5. Other complaints []

\section{Examination:}

- General examination.

- Cardiovascular system.

- Respiratory system.

\section{Per Abdomen:}

- UGI Endoscopic Findings.

- Biopsy (Taken/not).

- Impression.

\section{BIBLIOGRAPHY}

1. Edmonson J. History of instruments for gastrointestinal endoscopy. Gastrointest Endosc 1991;37:S27-S56.

2. Morrissey JF, Tanakay, Thorsen WB. The relative value of the Olympus Model Gt-5 Gastrocamera and Olympus Model Gi-F Gastrocamera Fiberscope. Gastrointes Endosc 1968;15:197-200.

3. Ebell MH. Evaluation of the dyspeptic patient: a costutility study. Journal of Family Medicine Practice 1997 Jun;44(6):545-55.

4. Locke GR, Talley NJ, Fett S, et al. Prevalence and clinical spectrum of gastroesophageal reflux in the community. Gastroenterology 1997;112:1448-1456.

5. Hirschowitz BI, Curtiss LE, Peters CW, et al. Demonstration of a new gastroscope. The "Fiberscope." Gastroenterology 1958;35:50-53.
6. Sivak MV. Videoendoscopy. In: Cotton PB, Tytgat GNJ Williams CB, Eds. Annual of Gastrointestinal Endoscopy. London: Gower Academic Journals 1988; Pp 115-125.

7. Johnsen R, Straume B, Førde OH. Peptic ulcer and nonulcer dyspepsia: a disease and a disorder. Scandinavian J Primary HealthCare 1988;6:239-243.

8. Jones R, Lydeard SE, Hobbs FD, et al. Dyspepsia in England and Scotland. Gut 1990;31:401-405.

9. Welch Allyn. Electronic endoscope for clinical trial1 1990:108-109.

10. Talley NJ, Weaver AL, Zinsmeister AR, et al. Onset and disappearance of gastrointestinal symptoms and functional gastrointestinal disorders. American Journal of Epidemiology 1992;15:165-177.

11. Drossman DA, Li Z, Andruzzi E, et al. US householder survey of functional gastrointestinal disorders: prevalence, sociodemography and health impact. Dig Dis Sci 1993;38:1569-1580.

12. Holtmann G, Goebell H, Talley NJ. Dyspepsia in consulters and non-consulters: prevalence, health-care seeking behaviour and risk factors. European Journal of Gastroenterology Hepatology 1994;6:917-924.

13. Agréus L, Svärdsudd K, Nyrén 0, et al. Irritable bowel syndrome and dyspepsia in the general population: overlap and lack of stability over time. Gastroenterology. 1995;109:671-680.

14. Klauser AG, Schindlbeck NE, Müller-Lissner SA. Symptoms in gastro-oesophageal reflux disease. Lancet. 1990;335:205-208.

15. Rudolf Schindler. The relative value of the Olympus model GT-5 Gastrocamera and Olympus model G1-F Gastrocamera Fiberscope. 1932;36:189-192.

16. Talley NJ, Colin-Jones D, Koch KJ, et al. Functional dyspepsia: a classification with guidelines for diagnoses and management. Gastroenterology Int 1991;4:145-160.

17. Devault KR, Castell DO. Guidelines for the diagnosis and treatment of gastroesophageal reflux disease. Practice parameters committee of the American College of Gastroenterology. Arch Intern Med 1995;155:21-65.

18. Hirschowitz BI, Curtiss LE, Peters, CW, et al. Demonstration of a new gastroscope. The "Fiberscope." Gastroenterology 1958;35:50-53.

19. Sivak MV. Video Endoscopy. In: Cotton PB, Tytgat GNJ, Williams CB, Eds. Annual of gastrointestinal endoscopy. London: Gower Academic Journals 1988; Pp 115-125.

20. Adang RP, Ambergen AW, Talmon JL, et al. The discriminative value of patient characteristics and dyspeptic symptoms for upper gastrointestinal endoscopic findings: a study on the clinical presentation of 1,147 patients. Digestion 1996;57:118-134.

21. Colin-Jones D, Bloom B, Bodemar G, et al. Management of dyspepsia: report of a working party. Lancet 1988;1:576-579. 